\title{
Correction to: Intravitreal bevacizumab injections combined with laser photocoagulation for adult-onset Coats' disease
}

\author{
Saemi Park ${ }^{1} \cdot$ Han Joo Cho ${ }^{1} \cdot$ Dong Won Lee ${ }^{1} \cdot$ Chul Gu Kim $^{1} \cdot$ Jong Woo Kim ${ }^{1}$ \\ Published online: 14 May 2019 \\ (C) Springer-Verlag GmbH Germany, part of Springer Nature 2019
}

Correction to: Graefes Arch Clin Exp Ophthalmol (2016) 254:1511-1517

https://doi.org/10.1007/s00417-015-3233-6

The published online version contains mistake.

The IRB number of the published article was A-2015-016 (page 1512,1st paragraph of the method section). However, the correct IRB number is A-2015-018.

Publisher's note Springer Nature remains neutral with regard to jurisdictional claims in published maps and institutional affiliations.

The online version of the original article can be found at https://oi.org/ $10.1007 / \mathrm{s} 00417-015-3233-6$

\footnotetext{
Han Joo Cho

chojoo@kimeye.com

1 Department of Ophthalmology, Kim's Eye Hospital, Myung-Gok Eye Research Institute, Konyang University College of Medicine, 156, 4ga, Yeoungdeungpo-dong, Yeoungdeungpo-gu, Seoul, South Korea
} 